\title{
A THERMODYNAMIC ANALYSIS OF URBANISATION
}

\author{
T. Srivenkataramana* \& T. Balakrishna Bhat**
}

\begin{abstract}
This article deals with application of concepts in thermodynamics to the process of urbanisation which is a global phenomenon. The disorder in urban environment due to high density of population is likened to the entropy concept of thermodynamics which is assumed to increase with population size. This introduces a check on urbanization and leads to a dynamic equilibrium between urbari and rural population components. A discussion is provided on a few factors which may be monitored to control urbanisation particularly in the less developed.regions of the world.
\end{abstract}

\section{Introduction}

The urbanisation process in the world today presents a variety of scenes. Many existing cities are growing at a rapid. pace. The number of cities has also been increasing steadily. The proportion of total world population living in urban areas has been rising (Table 1). Some cities have been growing together as a massive supercity with a denuded countryside.

A few cities have grown and reached a more or less steady size, while a few others which have grown too large have been forced to decrease their population and a

* Professor of Statistics, Bangalore University, Bangalore - 560056.

** Scientist, Defence Metallurgical Research Laboratory, Kanchanbagh, Hyderabad - 500058. 
variety of volcanic eruptions of human feelings and social movements have begun to surface.

\section{Table 1 : Pattern of urbanisation in some countries}

\begin{tabular}{|l|c|}
\hline Country & Percentage of urban population in 2002 \\
\hline China & 21 \\
India & 22 \\
Kenya & 13 \\
Nigeria & 20 \\
Pakistan & 29 \\
Ivory Coast & 38 \\
Egypt & 44 \\
Malaysia & 30 \\
Algeria & 52 \\
Argentina & 82 \\
Brazil & 68 \\
Columbia & 60 \\
\hline
\end{tabular}

This paper brings out a note of optimism in this apparently grim situation. It suggests that urbanisation reaches $a$ definite thermodynamic saturation which depends on the ratio of net earning potentials of rural and urban ways of life.

\section{Factors leading to Urbanisation}

There are a large number of factors that influence the urbanisation process. It is often suggested that urbanisation is an inevitable prerequisite for economic growth as it is more efficient to invest factors of production in urban areas than in rural counterparts. The easy availability of transportation, communication, administrative and financing networks makes cifies attractive to the investor. The available standard of living and more importantly, possibility of rapid rise to higher standards attract people to urban areas to provide the work force in factories, offices, markets, and many such ancilliaries. However, a thorough economic analysis suggests that urbanisation need not be inevitable and even modest governmental policies to improve quality of life elsewhere can restrain the migration of population (3). If economic growth were to be the sole determinant of urbanisation, the growth of urban agglomerates should inevitably be linked to the state of industrial economy. This is not always true and even a hopeless economy may allow cities to grow, for 
example, as did many African States and Saigoon a few years ago. People may gravitate to a city because the imported food and facilities are often dumped in the cities with little percolating to the hinterland. Migration may also be influenced by political conditions. The population of Saigoon declined purely by the Government's firm decision to push people out. In China, the lowest growth rate is found near Beiling and Shanghai, the big cities. As it happened in Ankara or Turkey disturbance can also push people out. Thus there appears to be a definite force of a general nature restraining urbanisation though the particular way it manifests itself may vary widely.

A generalization in this connection may be possible if we look at the human system as a whole and consider the basic thermodynamic forces controlling the flow of people. Thermodynamics, the field of averages and large numbers is perhaps eminently suited to study the behaviour of human masses.

\section{Thermodynamics of Urbanisation}

Cities are economic agglomerations for industries and business to expand. A city has in it people physically closer, more informed and connected better in several ways. The places of entertainment and expenditure have easy accessibility. In simple terms, people are able to earn more, and this gives them access to various forms of enjoyment. However, when more and more persons flock together, they begin to collide with one another on various counts and occasions to find themselves in conflict and as a result dissipative tendencies develop. Thus disorder insets in inspite of the apparent physical orderliness of the city environment. This disorder is intrinsic and can be compared to the entropy concept of thermodynamics. The entropy of urban system grows with its population size, eventually reaches such a level that it balances out the extra energy available through urban 'efficient' way of life. This introduces a check on urbanisation and the city attains a dynamic equilibrium with its rural counterparts. We may specify this equilibrium by equating the free energy of urban and rural areas in the following relation:

$$
E_{u}-T_{u} S_{u}=E_{r}-T_{r} S_{r}
$$

where $E$, S and T respectively denote energy, entropy and temperature per individual and the suffixes $u$ and $r$ indicate urban and rural life.

The standard expression for entropy is given by

$$
S=K(\ln N !) / N
$$


where $\mathrm{N}$ is the size of the population and K is Boltzmann's constant. Using (2) for urban and rural components, equation (1) can be rewritten as

$$
E_{u}-E_{r}=K T_{u}\left(\ln N_{u} !\right) / N u-K T_{r}\left(\ln N_{r} !\right) / N_{r}
$$

As an approximation we take $\ln N ! / N=\ln N$ and then (3) becomes

$$
E_{v}-E_{r}=K T_{v} \ln N_{u}-K T_{r} \ln N_{r}
$$

Define the proportions

$$
P_{r}=N_{r} / N \text { and } P_{u}=N_{v} / N
$$

where $P_{v}$ is of the nature of an index of urbanisation. Consider

$$
\begin{aligned}
\ln N U & =\ln \left(N-N_{r}\right) \\
& =\ln N\left(1-P_{r}\right) \\
& =\ln N-\left(P_{r}+P_{r}^{2} / 2+P_{r}^{3 / 3}+\ldots . .\right) \\
& =\ln N-P_{r} \ldots .
\end{aligned}
$$

ignoring second and higher degree terms in $\mathrm{P}_{r}$

Similarly

$$
\ln \mathrm{N}_{r}=\ln \mathrm{N}-\mathrm{P}_{\mathrm{v}}
$$

Substituting (5), (6) and (7) in the equilibrium condition (4) we obtain

$$
E_{v}-E_{r}=K \ln N\left(T_{u}-T_{r}\right)+K\left(T_{r} P_{u}-T_{u} P_{r}\right)
$$

Now without discussion we impose a condition that the urban and rural temperatures are identical and explain the physical implications of the condition a little later. Thus

$$
T_{v}=T_{t}=T \text { (say) }
$$

and equation (8) reduces to

$$
E_{u}-E_{r}=K T\left(P_{u}-P_{r}\right)=K T\left(2 P_{u}-1\right)
$$

since $P_{r}=\left(1-P_{v}\right)$.

Differentiating the terms in $(10)$ with respect to time t we get

$$
\left(E^{\prime}{ }_{u}-E^{\prime}\right)=2 K T P^{\prime}{ }_{u}
$$

where prime indicates differentiation with respect to time. 
Dividing both sides by $E_{v}$ 'we get

$$
\left(1-E_{r}^{\prime} / E_{v}{ }^{\prime}\right)=\left(2 K T / E_{v}{ }^{\prime}\right) P_{v}^{\prime}
$$

We designate $E_{r}^{\prime} / E_{v}^{\prime}$, the ratio of energy earning rates of rural and urban areas as f. Then (12) becomes

$$
1-f=\left(2 K T / E_{v}\right) P_{u}^{\prime}
$$

Rearranging (13) we get: $P_{v}^{\prime}=\left(E_{v}^{\prime} / 2 K T\right)(1-f)$

Integrating both sides with respect to $t$ we get

$$
P_{v}=\left(E_{v} / 2 K T\right)(1-f)+C
$$

where $\mathrm{C}$ is the constant of integration, which may be evaluated by imposing the boundary condition that when $f=1, P_{u}=0.5$, in view of equal rural and urban energy rates. This yields $C=0.5$. Thus ( 14 ) becomes

$$
P_{v}=0.5+\left(E_{v} / 2 K T\right)(1-f)
$$

Also in the limiting case of $f=0$, the rural energy rate is zero and $P_{v}$ should technically equal to 1 , so that (15) leads to $E_{v} / 2 K T=0.5$ or

$$
E_{u}=K T
$$

Using (16) in (15) we get $P^{*}=1-f / 2$

which corresponds to equilibrium urbanisation and it is uniquely dependent on the ratio of urban to rural earning rates. In the special case of equal rural and urban energy rates we have $f=1$ and the urbanisation index, $P^{*}$, should stabilize at a value of 0.5 .

\section{Discussion}

In section 3 we derived an equilibrium urbanisation proportion $\mathrm{P}^{*}$ based on thermodynamic arguments for sharing the total population between the two ways of life: urban and rural. By far the most important factor that affects saturation urbanisation is the factor ' $f$ ', the ratio of net energy earnings of rural and urban individuals. Indeed $f$ measures an important aspect of social justice. For simplicity of estimating $f$ we may use income as a near equivalent to energy but then one has to compensate for the additional expenses in city which bring no additional happiness to the urbanite as compared to the ruralite.

In this exposition we have used a new terminology "temperature" of a population. It is difficult to give a clear physical interpretation of this term. Nevertheless we may 
draw upon an analogy from the kinetic theory of gases in which a molecule with two degrees of freedom is treated to have a kinetic energy of KT. We thus obtained $E_{v}=K T$ in equation (16) for an individual who has essentially two degrees of freedom to move or choices to make "urban or rural", which is implicit in the model, though in practice there could be a few who stay in villages but work in cities and vice versa and pocess a dual status.

In the present analysis, we assumed urban and rural temperatures to be identical in equation (9) and taken together with equation (17) this implies that the global temperature is governed by the urban temperature. Since individuals are considered essentially mobile in this analysis, the rural folk can easily exchange information and acquire the tendencies of urban life and mentally attain the same temperature though this can be a slow process which precedes migration. One way to reduce the rate of urbanisation is to reduce the temperature which in some way is related to our material desires and the mental push we give to one another in our quest for materialistic life.

Striking differences in urbanisation patterns are apparent between the developed and the developing regions. In the former the proportion urban exceeds 0.5 while it is less than 0.5 in the latter, but unfortunately with a faster urban growth rate. As a result the share of developing regions in world's urban population has been rising (1). For instance, in the year 2000 over twice as many urban dwellers lived in developing regions as in developed regions ( 2 billion versus 0.9 billion).

An obvious way to check urbanisation is to reduce the difference in the rates of

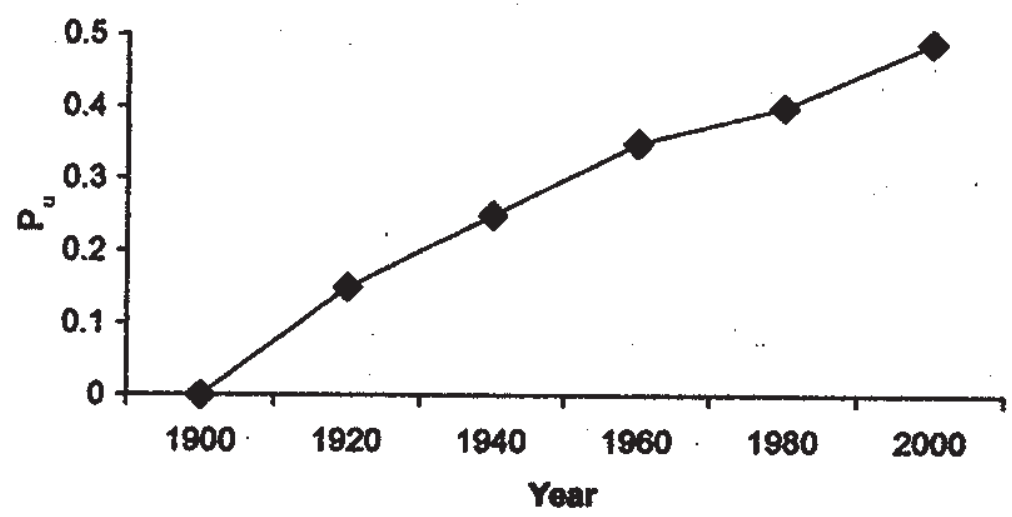

Fig. 1: Urbanisation trend in developing countries 
reward in the two systems of life for unit time of work. In Fig. I we have shown the way the global urbanisation factor has been evolving over the years in developing countries. It is seen that the total population ratio is still below 0.5 in this region. An unique opportunity for retaining a balanced world thus exists even today. However, as such the urbanisation ratio does not seem to saturate near 0.5 . This may be attributed to the unfavourable influence of $f$. In many populous countries a steady stream of newer technologies are imported from outside and fed into existing cities. There is no corresponding improvement in rural background leading to a very low ' $f$ '. Argentia, Brazil, Columbia, Pakistan, Egypt, India, China and many other countries come under this category, suffering anomalous growth due to maldistribution of the earning potential and a consequent low value of $f$. Thus steps to improve the value of $f$, the ratio of rural to urban earning rates, will help to decelerate urbanisation process in these parts of the world which a need of the hour.

\section{Remarks}

The concept of temperature used above is related to the state of mind and ones desire to acquire physical things. This tendency is communicated to each other through different media like the television, radio, newspapers, exhibitions and travel experiences. The other concept employed viz. that of energy is related to all the entities which can be used to produce happiness to individuals by direct use or in exchange transactions with the others. It is not just translational kinetic energy as in the case of molecules. The magnitude of energy is an unvarying function of the 'satistical temperature' of the system. It is always the same for any society. The higher the temperature, the greater the energy and conversely. A 'thermometer' to measure the temperature of a society is the concept of entropy which measures the internal energy of society that is not available for work.

\section{References}

1. United Nations Population Division (2002). World Urbanization Prospects : The 2001 revision, pp. 13-14.

2. World Bank Atlas (2002). World population data sheet of the Population Reference Bureau, Inc.

3. Vinninger, D.R. Jr. (1985). Scientific American 252, No. 4, p. 42. 